\title{
FROM INFORMAL EXCHANGES TO DUAL PRACTICES. THE SHADOWS OF THE ROMANIAN HEALTH CARE REFORM
}

\author{
CRISTINE PALAGA 1
}

\begin{abstract}
Motto:
Twenty years have passed and we're even more unstable than before. (D.N., senior surgeon)

Many forms of human suffering and many deficits in human flourishing are the result of existing institutions and social structures. (E.O. Wright, 2012:1)
\end{abstract}

\begin{abstract}
The current frailties of the Romanian health care system are often explained by resorting to the previous regime's institutional framework, rarely accepting that they are also the product of post-1990 reforms and the neoliberal means of system reconfiguration. This paper provides an ethnographic account of the ways in which two "products" of these reforms actively contribute to the augmentation of private medical services and to the diminishing access to quality care in the public system: the bureaucratization of primary medicine and the "dual medical practice". More specifically, I use the concept of "informal exchanges" in order to explore the variety of transactions that occur between patients and the health care staff and to document the means through which its main social actors understand, reproduce, legitimize or blame the very existence of these practices. Then, I analyze how referrals to private medical units increasingly replace informal payments, simultaneously laying even harder obstacles in the access to health care for those in need.
\end{abstract}

Keywords: informal payments, postsocialist health care reform, dual medical practice, private health care, medical anthropology

\section{Introduction:}

\section{brief incursion into the theory of informal exchanges}

Informal rewards for health-care services consist of payments, in money or in kind, that patients offer for services performed within the public health care system, which should be either free or significantly subsidized for

1 PhD Candidate in Sociology at the Babeș-Bolyai University Cluj-Napoca, e-mail: palagacristine@gmail.com. 
insured persons. Although hardly admitted in formal conversations, they are either expected or directly demanded by the healthcare providers (Ensor and Savelyeva, 1998:41).

In order to designate these payments, several labels have been used: "illicit payments", "under-the-table-payments", "unofficial donations", "small tokens of appreciation" etc. Mainstream reports on the health care services (such as those of the World Health Organization - WHO or the European Commission Eurostat) prefer to use the term "informal payments", due to its neutral charge. In the present paper, I have opted to use the concept of "informal exchanges" in order to explore the variety of forms of economic and symbolic transactions that occur between patients and the health care staff (nurses, doctors and other care providers) and to document the means through which the main social actors who take part in informal medical exchanges understand, reproduce, legitimize or blame the very existence of these practices.

Although extremely useful in understanding the phenomenon of the medical informal economy, macrostructural explanations cannot entirely exhaust the internal mechanisms of producing and reproducing informal exchanges. The object of these practices is by itself uncertain, possessing ambivalent qualities, sometimes paradigmatic for "commodities" otherwise pertaining to the anthropological category of "gift" (Stan, 2012). In order to capture "the ambiguous ways through which the formal and informal, the official and unofficial, the visible and invisible, the compliant and the incompliant" are produced (Koycheva, 2013: 4), a bottom-up analysis is required, beginning with the specificities of the medical act and what the narrative of the disease entails, going through probing the world of sensibilities and individual explanations for these informal practices and building up towards revealing the systemic outlets that underlie these practices. This study focuses on the latter aspect, aiming to point out the multiple ways in which two products of the liberal health reform allow for the proliferation and diversification of informal medical economy.

My ethnographic account, located in public hospitals from one of the largest Romanian university-centres, connects to a broader literature on the forms, frequency and relevance of these exchanges, particularly in those countries where the public health care system suffers from scarce financing and inefficient management. During the last three years, I had access to the field of daily interactions between patients and health care staff as a college student in Nursing, a status that allowed me to assist to various types of medical activities, to gain insights into their medical and social meanings, while being perceived by both patients and hospital staff as "an insider" and "an outsider" at the same time. Oscillating between the anthropological curiosity 
and the internalization of medical conduct, my research takes thus the form of a hybrid between the emic and the ethic perspectives. In order to obtain a grassroots view on the functioning of informal economy in medical care, I combined participant observation with semi-structured in-depth interviews. Seven public hospital departments became my main research sites; their ethnographies were supplemented with extensive conversations about the experiences of my subjects in other public or private clinics in which they were treated. In this way, I was able to re-construct their trajectories through different medical units and portray, from their view, the encounters and exchanges that took place with medical staff. The final textual form of field experiences is not void of "theory", as it assembles data so as to enlarge our understanding of informal exchanges and dual practices in the health care sector. But the ways in which the subjects themselves understand and confer meaning to the institutional context, which they are part of, remains an inseparable part of this explanation. Consequently, I have tried to shed light as faithfully as possible on their lived experiences and interpretations.

Specialized studies on the proportion and implications of informal payments for medical services made their debut in the early 1990s, when the interest of researchers focused mainly on analysing the means through which health systems throughout ex-communist Central and Eastern European states adapt to the new demands of democratic societies (Stepurko et.al., 2010), asking for better quality services and social fairness.

Indeed, in the "global South", the salience and amplitude of informal exchanges between the patient and the medical team can be deduced from the plurality of examples given by specific research covering vast geographic spaces. There has been an increased incidence of informal medical economy reported throughout all Central and Eastern European states (Hungary, Bulgaria, Greece, Albania, Russia, Poland, Romania etc.), and in 'third-world countries` such as Bangladesh, India, Nepal, Pakistan, Sri Lanka; Uganda, Mozambique, Rwanda, Ethiopia; Bolivia; Kazakhstan and Kyrgyzstan (Cherecheș et. al., 2013). However, there is a scarcity of studies on informal payments in the health care systems of high-income countries from Northern and Western Europe, North America or Australia, based on the assumption that the phenomena does not occur there (Cherecheș et. al., 2013). Some go even further and consider that informal payments constitute a relevant marker by which the degree of liberalization and democratization of economy can be measured. Yet, other studies provide evidence that forms of informal exchanges occur in "advanced" health-care systems as well. For example, the French perform informal payments in the field of surgery (Bellanger, 2000), while in Italy, medical licenses were suspended for a group of general practitioners as a result of an onerous contract with a private radiology 
centre, by which the doctors promised to deliver patients from the public healthcare sector to the private one (Turone, 1998 apud. Ferrinho et.al., 2004). Consequently, I suspect that the absence of documentation on such cases of informal exchange in the "global North" is rather the result of a policy of silence, an act of opacity and by no means solid proof of a high level of regulation and transparency at which the informal medical economy simply ceases to exist.

While the scientific community managed to standardize the term meant to nominate informal exchanges, the attempt to make an inventory of definitions on the phenomenon shows the fact that there is no unique, coherent or unanimously accepted manner of circumscribing the content and sphere of informal payments. Two distinct directions of categorizing the phenomenon can be established: a first line of thought that equates informal payments with acts of corruption and a second one, that distances itself from the legal status of these practices, instead concentrating on the method by which the protagonists of the exchange either legitimize or blame the system of informal payments (which nonetheless they both admit to exist and actively reproduce). Therefore, these are treated either as deviations from the legal payment system (Szende and Culyer, 2006 apud. Cherecheș et al., 2013: 110), being unavoidably bound to corruption (Liaropoulos et al., 2008), or as acts that can only be understood by registering and comparing the motivations beneath the reproduction of such practices by social practices.

\section{The Romanian Health Care System Reform}

Numerous studies regarding informal payments in the Romanian medical system concentrated thoroughly on delivering a critique of the phenomenon from a legalist perspective, being abruptly catalogued and dealt with as acts of corruption. It is assumed that under-the-table payments constitute a legacy of the communist past, when the quality of public services was so poor that individuals needed to "buy" private privileges that medical staff was able to preferentially channel from the public pool. The problem with this ways of establishing the genesis and causes of the informal medical economy is the disregard of the more recent structural arrangements which contribute to the reproduction of these practices. Without neglecting the genealogy of informal payments in the health care system and the fact that they were indeed performed during the socialist epoch as well, I try to analyse how the postsocialist institutional frames influence the reality of the informal economy of medical and health-care services. In line with Stan (2012), I posit that medical informal payments constitute individual responses to the "increased inequalities that followed the post-socialist redesign of the state" (Stan, 2012:65). 
As the state withdrew more and more from both economy and society, the post-socialist health reform projects, centred on encouraging private initiative and limiting patient access to the secondary and tertiary health care sectors, generated new forms of inequality and power asymmetries, fuelling individual strategies of informally procuring and providing better medical care. Post-socialist informal economic relations are theorized as temporary results of a transition from a rough bureaucratic state to a transparent and competitive economy (Kornai, 2000; Radin, 2009 apud. Stan, 2012). Therefore, informal exchanges are presented as relics of the communist past (to become extinct once the economy becomes fully liberal), instead of being asserted as direct repercussions of current economic and political transformations.

In the above-described framework, the internal causes of this phenomenon are blown out of proportion while the external ones are minimized, thus preventing any discussions on the negative effects of the globalization of capitalism (Kaminska, 2014). Therefore, we need to bring into attention the wider political and economic context in which these informal exchange relations are produced. Major imbalance was driven by budget cuts, the decentralization process, public-private partnerships and outsourcing in the health system, as well as by the emphasis on primary medicine along with the underfinancing of this field (Popescu, 2009). Consequently, I argue that we should focus on how the results of the health reform itself have maintained and augmented the medical informal economy rather than place the blame fully on the communist past.

Once we stop resorting to the anti-communist discourse for explaining all the social shortcomings and imbalances, we will be able to identify how certain structural factors yielding from the transition to capitalism and an insurance-based health care system (as opposed to the "communist" one) lead to propagating the negative aspects of medical informal exchanges (Stan, 2012).

The political, economic and social permutations that marked the last decade of the twentieth century heralded an indispensible set of reforms meant to stabilize Romanian society and situate it in the immediate proximity of a democratic organization. The reformist enthusiasm would strongly infiltrate the healthcare system; the necessity for restructuring finance flows and the means of organization of the entire Romanian health care system from the beginning of the 1990s was synthesized in the assertion: the "state as the poorest manager". The socialist system had guaranteed universal access to healthcare for the entire population through services provided within state-owned and stateadministered dispensaries and hospitals. This universalist desideratum was later denounced as tributary to a deficient and oversized infrastructure that was incompetently managed, thus inevitably headed for bad quality services and bankruptcy. 
After the fall of communism, the primary objective of the health reform was to reduce the budget load that was allocated to the health system. This was done mainly through introducing quasi-market elements, meant to stimulate real market conditions (ORS, 2012). Budget cuts and the new free-market imagery should both be understood as acts of state inactivity and responsibility transfer. While the post-socialist health reform initially concentrated on introducing market mechanisms (meant to optimize the management of clinical cases with minimal expenses), it later grew to openly support private initiative in the health care "business" (Stan, 2012). The state stimulated private medical practice, it supported the development of private clinics and medical laboratories and, last but not least, it encouraged people to contract private health insurance alongside the (still compulsory) public insurance (IER, 2002). Resources destined to the public health system were drastically cut as the state invested substantial sums of money into the development of a secondary, private health infrastructure (Stan, 2012). Part of the National Health Insurance House funds (between 5\% and $17 \%$ ) were oriented towards private hospital units, thus crippling the already limited budget for public hospitals. In 2006, there were 12 private hospitals in Romania; this number grew to 865 by 2012 (SAR, 2013:52). One can observe how, under state oversight, private clinics succeeded in tapping into the health insurance system, thus becoming profitable businesses. Without state support, this adjacent system of medical service would not have been sustainable due to the fact that "resorting to private services as an alternative to the public system is expensive even for those who earn average wages" (Dobos, 2006:5).

The apogee of liberalization measures for the healthcare system was reached in 2011, as the Government recommended the individual privatization of most public clinics; only teaching hospitals would remain state-bound. Also, some politicians openly spoke about the initiative to completely drop the national health insurance, and substitute it with private forms of insurance. After street protests and a long public debate, the initiative was abandoned. Then President Traian Băsescu demanded the withdrawal of the project, while ironically stating: "I see that a lot of people are satisfied with the current health system" ${ }^{2}$. Even today, as an image of symmetry, the preferential topic of discussion in the field of health reform is constituted by the necessity to privatize (partially or completely) the health system.

\footnotetext{
2 Source: $h t t p: / / w w w . m e d i a f a x . r o / s o c i a l / m i n i s t r u l-s a n a t a t i i-a-r e t r a s-d i n-d e z b a t e r e-p r o i e c t u l-$ legii-sanatatii-dupa-ce-basescu-a-cerut-public-acest-lucru-9146050

[last accessed: 10.05.2015].
} 


\section{The bureaucratization of primary medicine and the augmentation of private medical services}

Since 1994, one of the most hardened common denominators of all reformist initiatives has been the obsession for developing a type of primary medical assistance different than the one promoted within the Semashko model (simply put, the communist version of the Beveridgean model). The most important reform aimed at reducing the number of unnecessary hospital cases, due to the fact that many patients would access the tertiary health sector without actually requiring hospitalization in order to regain their health. Unnecessary hospitalizations had become a vacuum for funds throughout the entire system. Therefore, the main purpose of the strategies designed to control these unjustified entries in the hospital system was the consolidation of primary medical assistance (Rebeleanu et al., 2013:68). The general practitioner (also known as "family doctor") becomes the health reform hero, being the assignee of the role of the "gatekeeper", filtering all entries into the secondary and tertiary health sectors.

In the early post-socialist period, the governmental decision-makers imagined an alternative of providing primary medical services by overhauling the role of the family doctor. Therefore, the dispensaries that depended both financially and administratively on hospitals were turned into autonomous medical cabinets, in which the insured patient can benefit from prophylactic medical services (implementing vaccination schemes, sanitary education) as well as primary services (taking record of chronic patients, treating various minor pathologies and mediating between the patient and specialized medical practitioners). Despite the declared interest towards building a primary medical infrastructure, this domain was financially neglected by the government's policy-makers and the burden of healthcare costs shifted to the patients as copayments or informal payments in the public system, or as out-of-pockets expenditures in the private system (Popescu, Raț and Rebeleanu, 2008).

It is important to take note that family doctors/general practitioners are not state employees, but independent suppliers contracted by the National Health Insurance House, being mainly paid per number of insured patients registered on their list. This method of payment is called "capitation" 3 .

The scarcity of financial resources, the large number of patients per general practitioner, the increasing bureaucratization of their relations with the National Health Insurance House, as well as other medical institutions, led

\footnotetext{
${ }^{3}$ http://www.independentonline.ro/2015/02/13/Medicina-de-familie--cu-ziua--11173 [last accessed: 10.05.2015].
} 
to the failure of this new imaginary of primary healthcare services. The general practitioner cannot manage to promptly filter entries in the secondary and tertiary health sectors, whereas hospital treatment still demands most of the health care system's resources. In fact, the perverse effect of inefficient reforms throughout the field of primary medical care is not the decrease of patient access towards more specialized (and more costly) medical services, but instead the limited access to the most basic sector of the healthcare system (Vlădescu et al., 2002). There is no surprise that access to primary medical care has diminished and that hospital treatment remained ever-increasing on the background of severe underfunding of the main level of healthcare and lack of precise control over hospital admissions.

Therefore, the same reform that was meant to substantially reduce the number of patients who address the secondary and tertiary healthcare levels, actually transformed the general practitioner into an irritable bureaucrat, "who does anything but medicine" (S, age 32, male) 4.

Endless lists of patients, restricted budgets, limited numbers of daily consults, restrictions on recipe numbers and papers that vouch for necessity of specialist expertise as well as delayed expert examinations based on these vouchers constitute just a few of the reasons why patients choose not to consult the general practitioner:

Screw them all! (...) I went for a consult because of a rash and she [the general practitioner] told me that she could not give me a compensated prescription, that the share for the day was over (I, age 27, male).

This amount of demotivating factors in consulting the general practitioner has done nothing else than to create power differentials between doctors and to precipitate the reality of informal exchanges: the general practitioner lost his or her medical prowess in the eyes of the patient. They are no longer deemed capable of establishing accurate diagnostics or a proper treatment plan: "he tells you off the top of his head that you have this or that, maybe he gets it right, maybe not, it's like Bingo!" (U, age 43, male); "my doctor only prescribes me antibiotics, regardless of what I could have (S, age 22 , female).

The general practitioner is reduced to a managerial instance, as he or she is condemned to abide by the exaggerate formalities of the system. The actions of the general practitioner focus mainly on optimally accounting for medical cases, thus radically distancing oneself from their professional preparation up to

\footnotetext{
${ }^{4}$ Arbitrarily, the letters of the alphabet will substitute the name of the research subjects, in order to protect their identities. The purpose of these fictive nominations is to differentiate between various voices and interventions.
} 
that point where they start professing "anything but the job you trained for all these hard years" (dr. G., general practitioner, age 51, female). Along the major stress caused by ever-increasing number of audits done by National Health Insurance House, which...

... catches any and all irregularities. Just this month I've had to pay from my own pocket 'cause they said the paperwork wasn't done right" (dr. G., general practitioner, age 51 , female).

the general practitioner needs to manage all "disgruntled patients":

I do everything I can for them! There's no way I could do more! But they don't understand me, they think I'm the root of all evils! (dr. G., general practitioner, age 51 , female).

Most systemic imbalances transpire during consults with general practitioners; thus, all incisive reactions become visible in his or her presence.

The intensive bureaucratization of the general practitioner's profession severely damages the therapeutic nature of doctor-patient relationship. Discussions with general practitioners most often deviate from topics such as clinical symptoms or diseased-induced anxiety, into the realm of negotiating...

... what your compensated prescriptions are, what drugs you should buy, when to return for a ticket to a specialist" (Ş, 60, female).

Also, the reform of the primary medical system places the general practitioner on an intra-professional inferior position, an attitude that is reproduced among other medical practitioners:

A bunch of clerks. They're not even good clerks (dr. Z., male, surgeon, age 52).

People show up with some diagnostic ideas from the general practitioner that you can't believe your ears! (dr. M., male, otorhinolaryngologist, age35).

We should take into account the fact that patients are in a state of competition for resources, each of them vying for timely appointments, in order to complete those paraclinic examinations needed in order to establish an accurate diagnoses or in order to get compensated medical treatment. Thus, we can distinguish between two categories of patients: the first category of those that resort to "small tokens of attention" to lubricate their relationship with the general practitioner and the second category of patients, comprised of those people who avoid the general practitioner's filter and who would rather address specialists directly, either in their private offices or in gigantic queues during their schedules in public clinics, knowing that "if you're willing to spend, there's nothing you can't fix" (R, age 39, female). 


\section{Dual medical practice. Coercion versus voluntarism in the passage from informal exchanges in the public system to the formal purchasing of medical services}

In order to correct the underpayment from the public healthcare system, more and more medical practitioners resort to the so-called "dual medical practice". The term is used to describe the particular situation in which medicine is practiced in multiple sites, both public and private (Ferrinho et al., 2004). Dual medical practice designates the particular situation of those medical practitioners that simultaneously operate in public medical settings as well as in private medical establishments.

The private-public overlap in the health system reflects the "system's inability to ensure adequate salaries and working conditions" (Ferrihno et al., 2004:1). The dual medical practice has a compensatory effect, since doctors are constrained to round up the pay checks they obtain through practice in the public healthcare system by providing services in the private sector as well.

In the public healthcare sector, medical personnel of superior, medium and auxiliary status are paid with set specified wages, perceived as being unjustly low rewards for the preparation and work that are demanded of them. It is estimated that the largest share of medical practitioners' revenues originates from informal payments made by patients (IER, 2002: 54). The sums in question can double or even triple the official income of the medical employee (Ensor, 1998; Baschchieri et al., 2006).

Medics and nurses working in the public health sector are often labelled as unmotivated, unproductive, inefficient, and corrupt (Stepurko et al., 2010). These unfavourable labels are due to coping strategies through which the medical team is presumed to attempt to remedy their financial woes as well as the improper workplace conditions by demanding extra payments directly from patients. Because of several virulent anticorruption campaigns aimed at medical practitioners (Stan, 2012), these explicit demands became less frequent. Nonetheless, in parallel, several doctors started to use their own private practices as fronts that enable them to safely obtain extra-income without fear of legal repercussions. Dual medical practice triggers power-relations that lead to exclusion and layering; patients confronted with severe medical conditions, but who lack the resources needed in order to obtain private medical care, are often delayed or denied access to higher-grade medical specialists from the public medical sphere because of the fact that the schedules of said experts are oversaturated by cases addressed to their private practice.

Due to the fact that dual medical practice allows the exploitation of the institutionalized health access circuit, embedding the possibility of instilling a "predatory behaviour" throughout the medical ranks (Lambertini, 1999 apud. 
Ferrinho et al., 2004; Stan, 2012), numerous patients addressing public healthcare services are redirected to private clinics for "more thorough examinations" (A, age 43 , male).

The legal tagging of informal payments in the medical system as acts of bribery, seconded by ample negative media campaigns aimed at condemning them have lead to the apparition of nuances in the methods through which some physicians act compellingly against the patient's interest for personal gain. Through dual medical practice, the explicit initiation of informal relations is replaced by referrals towards private health clinics, in which the physician is either a practitioner or a shareholder. Therefore, patients pay extra for consults or procedures that are included in their insurance policy and could have just as well been performed in the public system. The act of constraining a patient to address private medical settings while being entitled to the same services in the public medical healthcare system constitutes a replacement of informal exchanges that is "risk-free"; moreover, this kind of constraint is hidden behind the false "choice" of using "shiny and friendly" private services.

The leniency of government authorities regarding the double employment of medical personnel in both public and private healthcare spheres generates a conflict of interest that causes patients/potential patients to be severely disadvantaged when claiming their rights as insured persons in the public system. As a pattern, most public employees provide similar services in private medical facilities, which allow them to treat patients that address the public sector, based on their public health insurance contract (Popescu, 2009). In this manner, a stream of patients between the public and private sector is created, flowing in both directions, according to the patient's or the doctor's strategic interests, thus eluding the filter role assigned to the general practitioner and saturating the tertiary health sector.

In the following paragraphs I will try to identify other consequences of this overlap between the private and public health sectors, mainly focusing on the repercussions that this specific institutional arrangement has at the individual level of the patient and the medical staff.

Both public and private systems are in fierce competition to attract as much as possible of the physician's working time. In Romania, a physician has 15 minutes allocated per each new patient in a hospital unit, while, in the private medical system the patient can take up as much of the physician's time as he or she is willing or able to pay for. In Cluj-Napoca, there are niches in the private healthcare system as well, where the time for a medical consult is strictly regulated (Oncological private medical cabinets, for example) - 15 minutes/per consult/per patient, but the patient as a paying customer has the possibility to pay extra in order to increase session time with the doctor. Due 
to the demand for prolonging the time allocated to a medical consult, the patient is indirectly encouraged to address the same doctor in his/her private cabinet:

When somebody's ill, they need the doctor to explain every detail to them using a rudimentary language. The doctor should speak gently and clearly. In fifteen minutes, for as long as the consult lasts, the doctor himself can't know for sure what disease he's dealing with. Of course you're gonna go see him in private, when he's got more time for you (L., licensed nurse).

Furthermore, the physician's dual professional practice represents a fundamental criterion by which patients guide their options when they resort to the private healthcare services. There are multiple arguments that justify this choice; first of all, a doctor that also performs public service should have greater professional expertise compared to one who is only employed in the private sector. Secondly, in this way they save the time and effort needed to pass through the public system:

I'd rather pay up straight to the privates than get an appointment with my general practitioner, who'll send me to clinics and infernal queues. This way, the doctor will treat me straight in the hospital; of course, I still need to go back for an occasional check-up at the private clinic from time to time, you know what I'm saying? (C, age 47, male).

Therefore, by going straight to the private sector, the patient manages to shunt the bureaucratic structure of the primary medical sector, thus gaining time that often proves to be invaluable, especially when dealing with a chronic or life-threatening medical condition.

Private medical services developed on the background of an acutely insufficient logistic capacity, characteristic to the state clinic circuit:

I've waited for an entire month to get an MRI, had some problems with those guys at the Insurance House (National Health Insurance House, n.n.), those lousy incompetents! (...) if I had the money to get it done in a private clinic, to avoid wasting time on the road and on hospital corridors, I wouldn't have given it a second thought! ( $F$, age 25 , female).

Dual medical practice is also perceived by patients as a chance to be treated by renowned doctors, experts whose professional success recommend them:

You know, one day you are completely healthy, you don't get a shot in your life and then, all of the sudden, they need to chop off your leg in order to keep you alive! (...) it is normal to want the best doctor to be the one who takes care of you and for that you must be ready to pay a shitload of money... (A, age 43, male). 
The vulnerability of the medical system toward the reality of informal exchanges needs to be justified through the perspective of the deep state of incertitude that accompanies the immediate need for medical treatment (Savedoff, 2006). One of the purposes of these informal practices is to reduce the uncertainty generated by disease and to soften the medical gaze.

Neoliberal health reforms aimed at transforming the beneficiary of the public health care system into a "client" of medical services, as an elongation of the idea that he would consume the health offer in the same manner by which he consumes other goods or services (Haug and Levin, 1983 apud. Henderson and Petersen, 2002). But this "health consumer construct" disregards the fact that "the individual continues to think and to act in a manner consonant with traditional models of patienthood" (Irvine, 2002:31). When confronted with the spectre of disease, individuals tend to act irrationally, abandoning themselves to physicians' judgements regarding medical procedures or treatment plan. However, unwilling to entirely release control, the patient "finds the motivation to pay extra even for the slightest improvement in the quality of health care" 5 .

The increasing number of private medical consults also represents the expression of a patient riot against the flawed manners of doctors professing in state clinics and hospital units. Suggestive in this regard is the statement of a patient (Z, age 24 , female), who saw the same gynaecologist after a certain timeframe, both in the public medical system and in his private office. While the private visit felt acceptable - "(...) he spoke nicely to me, he asked about my sexual history, he was kind and careful", the public emergency consult revealed an entirely different type of professional conduit:

Seriously, he almost started swearing at me. I told him that my ovaries hurt and he rushed me, told me to stop stating an opinion because surely I can't know enough anatomy. Then he told me to get undressed and, I swear, that was the most painful medical exam in my entire life (...) He prescribed some pain meds then sent me home. I was on the brink of telling him: You know how to behave in a private consult, don't you, you son of a bitch? (Z, age 24, female).

Another female patient, confronted with an uncannily similar case, concluded:

I think this is their money-making strategy. They act like shit, so that you get scared and then you go see them in private, 'cause you know they'll treat you right. But many women stop going altogether, since they have no money. And then you wonder why they are so many cases of cancer and other diseases among women (Al., age 36, female).

5 http://www.criticatac.ro/10640/sondajul-asiguratului-pierdut-despre-marketizarea-sanatatii/ [Accessed: 10.05.2015]. 
Predatory behaviour in clinical personnel (Lambertini, 1999 apud. Ferrinho et. al., 2004; Stan, 2012) constitutes a financial obstacle in accessing healthcare services and the long term effect of this manner of exercising the medical profession is that of delegitimizing the public health system (Ferrinho et. al., 2002; Doboș, 2005).

Private medical institutions have signed contracts with the National Health Insurance House, thus having the possibility to redirect patients towards the public hospital environment and to perform treatment inside the public sector (Popescu, 2009). Remaining in the field of Obstetrics and Gynaecology, a niche that is amply exploited by some doctors is providing prenatal care in the private medical environment while assisting birth or performing a caesarean operation in public hospitals:

All throughout my pregnancy, I used see him in his private office. He told me that he couldn't be reached at the [public] hospital, that he was too busy, that he didn't have time for consults there. I used to see him once a month; each consult was 150 lei [approximately 40 US dollars - n.n.] (...) I won't deny it, he was really nice to me. (...) He asked me where I wanted to give birth, in a private clinic or in the public hospital; I told him I wanted to do it at the hospital, cause I didn't have money to go to the private clinic. He said there was no problem, that we would do the C-section at the hospital. You see, I didn't want to do it naturally, I was afraid of the pain. (...) I gave birth assisted by the midwife, he only came to see me once. For his short visit I gave him an extra 1000 lei [approximately 250 US dollars - n.n.] (M, age 32, female).

It is important to note that the private medical health market cannot provide a wide variety of services. The tendency is towards "selecting those niches that provide the most demand", not towards ensuring a full range of healthcare services (Macq et al. 2000). Those doctors who use the publicprivate circuits in their personal interest, "bringing their clientele to the public hospital from the private medical centre" turn into "simple advertisers for their own offices, where they talk smoothly and do tests" 6 .

Relevant to this argument is the case of a patient who presents himself in a public hospital with a ticket from his general practitioner, in order to do a pulmonary X-ray:

I get scheduled on time (...), I do the scan and there I am, in front of the doctor, so he can check it out. He didn't really look at the film too much; he looked at me more, must have thought I had money judging by the way I was dressed. He then told me to look him up at his private office later in the afternoon, for

\footnotetext{
${ }^{6}$ http://www.criticatac.ro/20775/vrem-sntate-bun-pentru-puini-sau-ceva-sntate-pentru-toirespect-pentru-comunistul-arafat/[Last accessed: 10.05.2015].
} 
diagnoses and treatment. Pulled up a business card and told me to be there after 2 P.M. I did exactly as he said, what was I supposed to do? Pick a fight? Went to his office and paid 50 lei [approximately 12 US dollars - n.n.]. Good thing I didn't have to spend more! (Ct, age 50, male).

In order to get an overview on the ways in which different doctors allow and initiate the conflicting interference between the public and the private healthcare systems, I find that the following two paradigmatic situations are highly relevant.

The first example is that of a patient admitted for a surgical intervention in order to have a breast nodule removed. After a two day wait, the patient was directed to a certain private clinic, without being previously discharged from the hospital. When I talked to her during my nursing rounds, I found her crying and extremely agitated due to the fact that she had to borrow money in order to pay for a biopsy performed in a private centre, at the doctor's wish. Furthermore, the same medic had suggested that she have an MRI in the same private medical unit, for which she would have to pay another 750 Ron (approximately 170 US dollars). I was asked if those tests could also be performed inside the state hospital. Visibly puzzled, I told her it was possible, but that they require time and numerous papers that had to be emitted by various institutions. Feeling exhausted and powerless, the patient kept repeating: "I think it would be better if I just went home! (...) I already told the doctor that I can't pay for all this!" (XY, age 27, female). The next day, another patient held the same hospital room; I don't know if the operation took place or if the previous patient had been discharged on request.

Dual medical practice allows the doctor to recommend expensive paraclinic procedures, towards the purpose of rounding up his/her monthly income, instead of doing so for diagnostic reason. Some of the doctor's indications do not always have a medical justification, since sometimes there are less expensive methods to determine a diagnosis (Popescu, 2009). Just to be clear, this was not the case of the aforementioned patient, who needed those tests and whose contact with the perversities of the health system could very well cost her life. The dual medical practice allows the doctor to become homo economicus, strategically structuring his or her relationship with the patient with the (secondary) purpose of augmenting his income, without taking the physical and mental well-being of the patient into consideration.

The second paradigmatic example that documents the way in which the private health sector damages the interests of a patient already integrated in the public system follows a similar scenario. The patient showed up at the E.R., where... 
I waited for two whole hours, without exaggeration. Nobody gave a damn about me (...) Anyway, someone finally shows up and takes me to a bed so I can lie down. I was in some serious pain! I kept twitching around, had no idea what was happening. They finally gave me some painkillers (...), gave me an ultrasound, saw that I had kidney stones and they me to another clinical department (...) So let the fun begin! I wait for a while and a kind doctor shows up. He told me I needed surgery... (P, age 24, female).

After mentioning the necessity of a surgical procedure, the doctor designated his resident to give more details to the patients.

See if she can afford it and then come tell me, I heard him say to the resident. I was already starting to panic (P, age 24, female).

The medical resident was therefore tasked with detailing the conditions for the patient to regain her health:

He told me that I had to go to a private clinic, said that it wasn't a complicated procedure, but that general anaesthesia was needed and that it would cost 300 Euros (P, age 24, female).

The patient was never presented with the possibility of having the same procedure performed in a public hospital. Despite her initial hesitation, she finally accepted to have the surgery performed in the private clinic; intense pain, added to the fear of what might happen if the surgery was postponed were the main determining factors for accepting the terms set by the doctor through his resident. The check-ups that followed after the surgery were performed in a public hospital. "I never had to wait in line, was always the first to get to the doctor", remembers P. Shortly after the intervention, she needed to undergo another procedure. I had the chance to accompany her to the hospital. She was anxious about the fact that the doctor might ask for more money:

Seriously! [laughing, n.n.] If he wants more money, I'll just keep this tube inside me, cause I have nothing more to give! ( $\mathrm{P}$, age 24 , female).

She addressed the receptionist, mentioning that she was scheduled for a minor intervention. Following standard procedure, the nurse requested the necessary documents for undergoing surgery in the public health sector: a medical letter, signed by the general practitioner, a receipt attesting that she was medically insured and, finally, a check in ticket from a specialist clinician. $P$ could not produce any of the documents listed above: 
I froze when she asked me for those papers. I had never been in a hospital before and I didn't know that I needed letters or receipts, also the doctor never mentioned any of those ( $\mathrm{P}$, age 24 , female).

Thinking that she might need to reschedule the intervention, the patient waited for the doctor; when he finally arrived, the medic got angry at the nurse for making "miss p wait for so long". "She doesn't need anything (any of the above-mentioned documents, n.n.). Have her ready and prep the room", were the doctor's orders. Feeling quite bad for the entire situation, $p$ apologized to the nurse, telling her she would bring all the necessary papers in the future, a moment in which the nurse reacted by saying: "the doctor is a grown-up! He knows what to do so he doesn't get into trouble!" (N, nurse).

Within the timeframe that elapsed between the moment in which the patient was taken into the O.R. and the time they brought her back in the ambulatory, I witnessed a heated discussion about a patient who was also "advised" to have surgery in a private clinic. The patient in question explained to his entourage, on a high tone, that the nerve and lack of work ethic of Romanian medical practitioners had reached unprecedented heights. For a short period of time, the waiting room turned into a space in which the patient openly denounced the abuse to which he was subjected:

What's happening here is absurd. So it's normal for them to say that I can only have the operation at a private clinic? What's wrong with the hospital, sir?! He tells me that aaaall beds are occupied and I need to wait until one frees up, but there's no such problem at the private clinic, where it can be handled i-mme-diate-ly [he emphasizes the word - n.n.]. It's clear that they can't squeeze enough money from the sick people in hospital (...) A bunch of crooks and rascals! (V, male, approx. 40 years old)

Promptly, a nurse intervenes in order to calm the spirits - other patients were stirred by the man's speech, jumping in to the conversation:

Where do you think you are? This is a hospital and not the circus! You don't yell around here, 'cause there are sick people around. (...) also why didn't you get shoes? [when entering the medical unit, patients and visitors are obliged to wear some protective plastic material on top of their shoes - n.n.]. Do you want to bring germs from outside, so that ill people can get worse?! (K, female, approx. 30 years old)

The symbolic pollution that this patient created by daring to signal out a flagrant violation of his fundamental right to access quality public medical healthcare was transformed into an inconsistent speech on the means by which the patient interrupts the working flow of the unit. The nurse's recourse 
to regimentation, to asepsis-antisepsis norms and the high degree of organization that constitute the functioning model of any hospital unit could do nothing else but deepen the discordance between the pretended state of things, which was supported by the medical staff and the reality experienced by the patient.

\section{From patients to clients. (Not so) final thoughts on the subject matter}

Using ethnographic details to illustrate how abstract, macrosocial instances outline the lives of particular individuals, I strove to point out, throughout this paper, how the perseverance of healthcare reform initiatives in the direction of developing the field of primary medicine and of aligning the medical system to liberal market expectations generated new forms of informal payments, diversifying and deepening patients' uncertainty.

As the state withdrew more and more from both economy and society, the project of post-socialist health care reform, centred on encouraging private initiative and limiting patient access to the secondary and tertiary healthcare sectors, generated new forms of inequality and power asymmetries, fuelling those individual strategies that informally procure/provide better medical care. The general practitioner is reduced to a managerial instance, as he or she is condemned to abide by the exaggerate formalities of the system. Endless lists of patients, restricted budgets, limited numbers of daily consults, restrictions on recipe numbers and papers that vouch for necessity of specialist expertise as well as delayed expert examinations based on these vouchers constitute just a few of the reasons why patients choose not to consult the general practitioner anymore. This amount of demotivating factors has done nothing else than to create intra-professional power differentials between doctors and to precipitate the reality of informal exchanges. Thus, we can distinguish between two categories of patients: the first category are those who resort to "small tokens of attention" to lubricate their relationship with the general practitioner, while the second category is comprised of those who avoid the general practitioner's filter and who would rather address specialists directly, either in their private offices or in gigantic queues during their schedules in public clinics, knowing that "if you're willing to spend, there's nothing you can't fix" (R, age 39, female).

Also, the simultaneity of medical practice in public and private segments has two immediate effects. On the one hand, it minimizes the filter role of general practitioners, who become incapacitated in their medical role and deprived of real decision-making power over who should and who shouldn't receive specialized medical consultation and treatment, based on their health status. On the other hand, it deepens social asymmetries regarding access to 
the secondary and tertiary healthcare sectors: some patients can afford paying for services and they consequently have access to treatments that are not necessary considering their health status, while others are cut out from services they need but which they are unable to pay for.

Both patients and medical care personnel identified means of coping with systemic problems, but these coping mechanisms are unevenly distributed: they require physicians to hold a private practice alongside their public employment, and demand extensive financial resources from the patients. Put otherwise, doctors have unequal access to the resources needed to provide quality care, and patients face unequal possibilities to use them. These systemic problems resulting from the post-socialist reconfiguration of the health care system (and not as a consequence of the communist past as such) could hardly become extinct once market principles further penetrate the functioning of medical care.

\section{REFERENCES}

Baschieri A., Falkingham J. (2006). Formalizing informal payments: The progress of health reform in Kyrgyzstan. Central Asian Survey, 25(4):441- 460.

Cherecheș, R.M., Ungureanu M.I., Sandu, P., Rus I. A. (2013). Defining informal payments in healthcare: a systematic review. Health Policy, 110(2-3):105-114.

Doboș, C. (2006). Dificultăți de acces la serviciile publice de sănătate în România. Calitatea vieții, XVII(1-2):7-24.

Ensor, T., Savelyeva L. (1998). Informal payments for health care in the Former Soviet Union: some evidence from Kazakstan. Health Policy and Planning, 13(1):41-49.

Ensor , T. (2004). Informal payments for health care in transition economies. Health Policy, 58(2):237-246.

Ferrinho, P., Van Lerberghe, W., Fronteira, I., Hipólito, F., Biscaia, A. (2004). Dual practice in the health sector: review of the evidence. Human Resources for Health, online source: http://www.ncbi.nlm.nih.gov/pmc/articles/PMC529467/ [Last accessed: 07.06.2014].

Irvine, R. (2002). Fabricating 'health consumers` in health care politics. In S. Henderson, and A. Petersen (eds.). Consuming Health. The Commodification of Health Care. London: Routledge, pp. 31-47.

Institutul European din România - IER (2002). Studii de impact realizate în cadrul proiectului PAIS I. Sinteze. Studiul 10, pp. 49-82. http://www.ier.ro/documente/studiideimpactPaisl), [Last accessed: 07.06.2014].

Kaminska, T. (2014). Informal Health Economics in Ukraine. Management in Health, VIII(1), pp. 5-7. 
Koycheva, L. (2013). Fading Ink and the Elusive State: Technologies of (Dis)Trust, The Permeability of Paperwork and Postsocialist Modernity in Bulgaria. Online source: http://psychole.soup.io/tag/Europe, [Last accessed: 10.03.2014].

Liaropoulos L., Siskou, O., Kaitelidou D., Theodorou M. (2008). Informal payments in public hospitals in Greece. Health Policy, 87: 72-81.

Macq, J., Ferrinho, P., De Brouwere V., Van Lerberghe W. (2001): Managing health services in developing countries: between the ethics of the civil servant and the need for moonlighting. Human Resources for Health Development Journal, 5: 17-24.

Popescu, L., Raț, C., Rebeleanu, A. (2007). Self-assessed health status and satisfaction with health care services in the new member states of the European Union. Studia UBB Sociologia, 52(2): 125-150.

Popescu, L. (2009). Serviciile de îngrijire a sănătății [Health care services]. In M. Preda (ed.), Riscuri și inechități sociale în România. Raportul comisiei prezidențiale pentru analiza riscurilor sociale și demografice [Risks and inequities in Romania. The report of the presidential commission for the analysis of social and demographic risks]. Iași: Polirom, pp.152-167.

Rebeleanu, A., Şoitu, D., Gavrilovici, C., Oprea, L. (2013). Echitate și respectarea drepturilor asiguraților - implicații asupra accesului la asistența medicală primară [Equity and respect for the rights of insured persons - implications for access to primary medical care]. Revista Română de Bioetică, 11(2): 66-76.

Savedoff, W. D. (2006). The causes of corruption in the health sector: a focus on healthcare systems. In Transparency International. Global Corruption Report 2006: Special focus on corruption and health. London: Pluto Press.

Societatea Academică din Romania - SAR (2013). Raportul de Analiză și Prognoză [Analysis and Prognosis Report]. pp. 52-66.

http://sar.org.ro/wp-content/uploads/2013/03/Politica-de-sanatate.pdf [Last accessed: 14.03.2014].

Stan, S. (2012). Neither commodities nor gifts: post-socialist informal exchanges in the Romanian healthcare system. Journal of the Royal Anthropological Institute, 18: 65-82.

Tepurko, T., Pavlova, M., Gryga, I., Groot, W. (2010). Empirical studies on informal patient payments for health care services: a systematic and critical review of research methods and instruments. http://www.biomedcentral.com/1472-6963/10/273

[Last accessed: 12.05.2014].

Vlădescu, C., Scîntee, G., Olsavssyky, V. (2008). Romania. Health system review. Health Systems in Transition, 10(3):1-172.

Wright, E.O. (2012). 2011 A.S.A. Presidential Address: Transforming Capitalism through Real Utopias. American Sociological Review, 20(10):1-25. 